Langton D, Hashmi M, Green S, OBrien S, Duffy P, Scott S, Shaw N, Brewster N, Deehan D, Jafri A, Cooke N, Tulloch C, Logishetty R, Loughead J, Sidaginamale R, Meek D, Longstaff L, Nargol A, Nanu A, Holland J, Joyce T, Ahmed I, Foguet P, Sprowson A, Lord J, Avery P, Scholes S, Waller S, Murray H, Bone M. Investigation of Taper Failure in a Contemporary Metal on Metal Hip Arthroplasty System Examination of Unused and Explanted Prostheses. Journal of Bone and Joint Surgery 2017, 99(5), 427-436.

Copyright:

This is the authors' accepted manuscript of an article that has been published in its final definitive form by Journal of Bone \& Joint Surgery, Inc. 2017

DOI link to article:

http://dx.doi.org/10.2106/JBJS.15.00917

Date deposited:

$06 / 03 / 2017$

Embargo release date:

01 March 2018

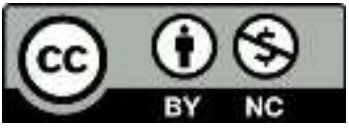

This work is licensed under a Creative Commons Attribution-NonCommercial 3.0 Unported License 


\section{INVESTIGATION OF TAPER FAILURE IN A CONTEMPORARY METAL ON METAL HIP ARTHROPLASTY SYSTEM THROUGH EXAMINATION OF UNUSED AND EXPLANTED PROSTHESES}

\section{The Northern Retrieval Registry}

David Langton, Munawar Hashmi, Stephen Green, Shaun O’Brien, Patrick Duffy, Stephen Scott, Nicholas Shaw, Nigel Brewster, David Deehan, Anwar Jafri, Nicholas Cooke, Chris Tulloch, Raj Logishetty, Jonathan Loughead, Raghavendra Prasad Sidaginamale, Dominic Meek, Lee Longstaff, Tony Nargol, Ananda Nanu, James Holland, Thomas Joyce, Imran Ahmed, Pedro Foguet, Andrew Sprowson, James Lord, Peter Avery, Susan Scholes, Susan Waller, Helen Murray, Martin Bone.

\section{ABSTRACT}

Background: Large diameter (LD) ( $\geq 36 \mathrm{~mm}$ ) metal on metal (MoM) total hip replacements (THRs) have been shown to fail at an unacceptably high rate. Globally, the Depuy Pinnacle prosthesis was the most widely used device of this type. There is evidence to suggest that one of the main reasons for the poor clinical performance of LD MoM prostheses is due to metal debris release from the head stem taper junction - taper junction failure. The variables leading to taper junction failure have yet to be fully elucidated and quantified. The aim of this study was to investigate variation in the as manufactured finish of the female taper surface and to determine its influence on material loss. We hypothesized that rougher surfaces with higher relative material peaks would be significantly associated with greater taper wear rates.

Methods: We analysed 93 Articuleze $36 \mathrm{~mm}$ bearing diameter femoral head tapers which had been used in combination with a Corail titanium uncemented stem. The influence of the surface topography of the as manufactured female taper surface on taper wear was examined by means of a multiple regression model taking into account other known variables.

Results: We identified great variation in the as manufactured surface finish of the female taper surface with a range of measured Ra values from $0.14-4.20$ microns. The roughness of the female taper surface appeared to be the most important variable associated with taper wear $(p<0.001)$. The best fitting regression model including duration in vivo, head offset, Rpk value, stem shaft angle and bearing surface wear rate explained approximately $44 \%$ of the variation in taper wear rates.

Conclusions: The roughness of the female taper surface appears to be a significant factor in metal debris release from head stem taper junctions.

Clinical relevance: This study shows evidence that hitherto unappreciated variations in manufacturing processes may have a major impact on the clinical outcomes of patients.

\section{BACKGROUND}

Large diameter (LD) (36mm diameter and greater) metal on metal (MoM) total hip replacements (THR) have been shown to fail at an unacceptably high rate, exposing many thousands of patients to unnecessary revision surgeries. Globally, the Depuy (Warsaw, Indiana) Pinnacle prosthesis was the most widely used device of this type.(1)

There is evidence to suggest that one of the reasons for the poor clinical performance of LD MoM devices is due to an adverse immune response to metal debris generated from the taper junction.(2) The "taper junction" (sometimes referred to as a "Morse taper") is the connection formed by the clinician during the operation when the femoral head is impacted, press fit, on to the femoral stem. 
When the taper junction is loaded, micromotion between the femoral head and femoral stem can lead to metal debris release through fretting (figure 1).(3) The ensuing clinical problems resulting from this debris release encompass a spectrum of clinical manifestations including bone and soft tissue lesions, which have previously been brought together under the umbrella term "adverse reactions to metal debris".(4) Emerging reports indicate taper failure is not a problem specific to MoM prostheses. $(5,6)$

The potential for metal release from taper junctions was well documented in a collection of papers from the American Society for Testing of Materials (ASTM) in 1997.(7) These papers concluded that a number of design and manufacturing variables contribute to material release and it was noted that "orthopaedic industry standards for the specification of Morse tapers are nonexistent, and typical medical taper tolerances are eight-fold lower than those used in the automotive and machine tool industries."(7)

We have previously described in detail the characteristics of taper failure in Depuy large diameter MoM hips.(8) We have also presented evidence to suggest that titanium alloy stem tapers can wear the female cobalt chrome ( $\mathrm{CoCr}$ ) surface secondary to a galvanic corrosive process.(9) Consistent with this finding, it has been shown that rougher male tapers are associated with greater rates of material loss at the female taper surface. $(10,11)$ During the course of our investigations, we identified what appeared to be wide variation in the as manufactured surface finish of the female taper (see figure 2). In the current study we aimed to quantify the extent of this variation and determine its influence on metal debris generation. Similar to the effect observed with a roughened male taper surface, we hypothesised that a rougher female surface would be associated with greater rates of material loss. More specifically we hypothesised that higher material peaks (quantified in the Rp and Rpk measurements) which would be exposed to the shearing effects at the material interface, would be the most significant factor.

\section{MATERIALS AND METHODS}

\section{The 36mm Corail Pinnacle MoM hip system}

The Depuy Pinnacle hip system consists of a modular titanium acetabular shell into which can be press fit a liner manufactured from $\mathrm{CoCr}$ ) metal (to form a MoM hip), ceramic (as part of a ceramic on ceramic ( $\mathrm{CoC}$ ) hip) or polyethylene, to form a metal on polyethylene (MoP) hip. The MoP and CoC versions remain on the market. The MoM version was withdrawn from use for commercial reasons in 2013. This study focuses solely on the $36 \mathrm{~mm}$ bearing diameter MoM system.

Two types of femoral heads can be used in the $36 \mathrm{~mm}$ Pinnacle MoM arthroplasty system. They are identical in terms of materials and taper finish however they have different cone angles for use with different types of Depuy femoral stems. The Articuleze is designed for use with 12/14 dimension stems (the most common of which in the United Kingdom is the Corail) and the Ultamet is designed for use with 11/13 dimension stems, the most common being the SROM stem (both DePuy). The Articuleze is the focus of this study.

\section{Analysis of unused components}

We obtained seven sterile Articuleze femoral head components which had breached their use by date from our hospital stock. We used a Mitutoyo SJ400 contacting profilometer (Mitutoyo, Tokyo, Japan) to examine the surface finish of the internal head taper. In this paper we refer to this surface as the "female taper surface". A profilometer provides a detailed cross sectional trace of the metal surface, accurate to the sub-micron level (figure 2). This two dimensional trace in simplistic terms describes the roughness of the material surface with respect to the peak heights and valley depths of the metallic surface relative to the core material. As well as graphical representation of the material surface, profilometry also quantifies a number of internationally recognised surface parameters. The most commonly recognised is the roughness average value ("Ra").(12) Five continuous traces were taken in accordance with the international standard guidance for surface roughness assessment ISO 4288.(12) Each measurement length was $0.8 \mathrm{~mm}$, giving a combined trace length of $4.0 \mathrm{~mm}$. Table 1 lists the measurements that were recorded along with their mathematical basis. 


\section{Assessment of explanted components}

We then performed the same measurements on identical explants provided from the Northern Retrieval Registry (NRR).(13) The Northern Retrieval Registry (NRR) is an initiative involving surgeons and engineers in the North of England. Analysis of explanted orthopaedic devices is conducted on a routine basis for all retrieved components. The NRR involves seven hospitals in seven cities across the United Kingdom (NRES reference 09/H0905/41).

Explant analysis and the identification of the unworn, as manufactured surface

On removal at revision surgery, explants were immediately immersed in $10 \%$ formalin solution. On receipt for analysis the components were washed with copious amounts of water and the surfaces rubbed gently with the fingertip to dislodge weakly adherent material. Taper surfaces which had not come into contact with other metal surfaces (distal to the base of the male taper) during their service life typically were free of debris (figure 1). We, along with other investigators in the field, have published literature on the ability to recognise and measure the as manufactured material surface of explanted components. $(2,8,14-16)$

The unworn sections of the head tapers were assessed using the same equipment. However, due to the reduction in the length of the original as manufactured surface available for analysis, two continuous traces were taken (rather than five) resulting in a reduced total measurement length of $1.6 \mathrm{~mm}$. This is discussed in depth in Appendix 1. Figure 2 shows examples of the variations in used and explanted Articuleze and Ultamet head taper finishes in the study.

Is variation in the roughness of the as manufactured surface associated with increased metal debris generation from the taper junction?

All Articuleze 12/14 heads used with Corail stems received at the NRR up to August 2014 underwent full volumetric wear assessment of the femoral and corresponding acetabular bearing surfaces as well as the articular surfaces of the taper junctions. This was done using a coordinate measuring machine (CMM) (Legex CMM; Mitutoyo, Tokyo, Japan) with an accuracy of $0.8 \mu \mathrm{m}$. The technique we used to obtain volumetric measurements of the bearing surfaces of MoM components has previously been published.[11] We used the same CMM with a $0.5 \mathrm{~mm}$ probe in combination with a similar custom designed Matlab programme (The Mathworks Inc., Natick, Massachusetts) to analyse the female taper surfaces. This methodology has previously been validated and published.( $(8,10,17)$ As well as quantification of material loss, these techniques also allow visualisation of the distribution of wear by generating a wear map (figure 3). Using gravimetric analysis of a variety of different cones as the benchmark measurement technique, our taper analysis was found to have a median (range) error of $0.05 \mathrm{~mm}_{3}$ with a range of -0.32 (under measurement) to +0.24 (over measurement). The practical approach to the calculation of volumetric wear and the accuracy of such calculations is detailed in (Appendix 2).

We have previously identified a number of variables associated with taper debris generation, which were in agreement with the results from other investigators. $(7,18)$ These variables include head diameter, head offset, material combination and taper angles. We were previously unable to demonstrate a relationship between taper wear and femoral stem offset(10), bearing surface wear rate or cup position(8). For this study, in order to eliminate a number of confounding variables, we selected only DePuy $36 \mathrm{~mm}$ diameter Articuleze 12/14 head tapers which had been mated with Corail stems. The Corail is an uncemented stem manufactured from a standard medical grade Ti6Al4V alloy.

\section{Univariate analysis}

Total volumetric wear values were converted initially to mean annual wear rates by dividing by the number of years in vivo. Spearman Rank correlation was then used to examine the relationship of mean annual wear rates to each individual variable. Variables under investigation were: patient factors (patient sex; patient age at primary surgery; acetabular shell size (determined by patient anatomy); presence of bilateral Pinnacles); implant factors (duration in vivo; femoral head offset; female taper angle; femoral stem shaft angle) and manufacturing factors (surface roughness parameters). The results of these tests are given in table 2. Multiple regression analysis 
Next, total volumetric values were log transformed to achieve an approximately normal distribution. With log transformed taper volume loss as the response variable, stepwise multiple regression was performed with all patient and implant variables included. Given the number of surface roughness parameters, and their inter-correlation (table 3), our initial focus in the statistical analysis of roughness was the Rpk (reduced peak height) value. The Rpk value is a measure of the average height of the protruding peaks above the roughness core profile. In layman's terms it is a measure of how "mountainous" the material surface is. A high Rpk value indicates there are several peaks standing proud of a material surface. In a wear process, it is recognised that higher Rpk values can be undesirable hence our reason to focus on this parameter. Forward and backward stepwise approaches were used to ensure there were no practical differences in the statistical methods used. In order to test our hypothesis that Rpk would be the most significant surface roughness parameter, a larger stepwise model was conducted including all measured surface roughness parameters to determine their relative influence on material loss.

Male taper analysis

In a minority of cases, the femoral stems were also explanted. In order to investigate the variation in taper angles and surface finish of the Corail stem tapers, they were analysed using the surface profilometer and CMM. To ensure accurate assessment of the variation in topography secondary to the manufacturing process, only peak to peak distances were recorded from the profilometry analysis. This was because, in theory, all of the male taper could have contacted the female taper surface resulting in minor surface changes which may have significantly altered sub-micron measurements such as Ra values. Male taper cone angles were obtained from the CMM using methodology described in detail in a previous publication.(10) Five unused Corail stems which had breached their use by date were also obtained for analysis.

\section{RESULTS}

Analysis of unused female tapers

Seven unused Articuleze femoral heads underwent roughness analysis. The mean (range) Ra value was 0.84 microns $(0.19-1.80)$. Figure 2 shows representative traces, with a regular machining pattern clearly identifiable.

Analysis of explanted female tapers

In total, 95 Pinnacle femoral heads from 83 patients had been retrieved. Two heads with large offsets ( 8.5 and 12 ) could not be used in the analysis due to the extent of the surface disruption. Patient demographics, implant details and reasons for revision are shown in table 4. 46 were KLA Corails (with a stem shaft angle of $125^{\circ}$ ) and the remainder had standard $135^{\circ}$ stem shaft angles. Volumetric material loss values were non parametrically distributed $(p<0.001$, Shapiro Wilk test for normality).

\section{Surface roughness of the as manufactured female taper surfaces}

Surface topographies of the unworn female taper surfaces varied markedly (table 5). Approximately $25 \%$ of the samples were found to have very smooth surfaces finishes as shown in figure 2. Beyond this, tapers were found to have variable finishes with marked differences in roughness, peak to peak differences, skewness and peak to valley distances (figure 2). These differences were distributed apparently randomly with no association with lot number or date of implantation. Head tapers with Rpk values in the fourth quartile of the range of Rpk distributions had the highest rates of volumetric loss compared to the other heads ( $p<0.001$ Mann Whitney test)(figure 4).

Univariate analysis

Results of the univariate analysis are shown in table 2. Rpk was found to be the variable with the greatest power to explain the variation in taper wear rates.

Multiple regression analysis

Stepwise regression models returned consistent results using either forward, backward or best fitting methods. Rpk value alone provided approximately $19 \%$ of the variation in the taper wear measurements. Duration in vivo was the next most influential variable, followed by femoral head 
offset. There were trends towards increasing taper wear with a 125 degree femoral stem shaft angle, larger female taper angles and lower bearing wear rates (table 6).

Adjusted $R_{2}$ values for all statistical approaches varied between 35 and $45 \%$, with $p$ values for all models $<0.001$ (see table 6). The essential findings of the multiple regression model are illustrated most simply in figure 5 . Articuleze heads with +5 and +8.5 offsets with Rpk values greater than the median had over a ten-fold increase in taper wear rates compared to low offset $(-2$ and +1.5$)$ heads with Rpk values below the median value.

Analysis of unused male tapers

Five Corail stems were available for analysis. There was little variation in the cone angle between samples, with a mean (range) of $5.662^{\circ}(5.651-5.684)$. The machined finish of the taper surface was consistent, with peak heights of 14 to 15 microns equally spaced a mean distance of 195 (189-201) microns apart.

\section{Analysis of explanted male tapers}

20 Corail stems were explanted. In only two revisions was a loose stem thought to be the primary cause of failure of the hip. In the remaining cases, there was stem loosening associated with gross metal reactions, in the remainder the stems were removed due to concerns over damage to the male taper. The mean (range) cone angle was $5.664^{\circ}(5.647-5.687)$. The machined finish to the taper surface was consistent, with peak heights again of 14 to 15 microns equally spaced a mean distance of between $196(185-228)$ microns apart.

Having identified the dominant variables of Rpk, duration, SSA and head offset from the analysis described above, a similar statistical approach was adopted to determine the impact, if any, of the male taper variables on female taper wear rates. Neither the male taper angle, the female/male taper angle mismatch, nor the peak to peak distance of the male taper surface was found to have any impact on the regression model.

Mechanism of material loss

To further examine material loss at the taper surface, full length profilometry studies were performed on the explanted components. A representative trace is shown in figure 6 . Patterns of material loss were consistent, with loss of height of material peaks in the transition zone and imprinting of the male taper grooves deeper in the engagement area. The wearing away of the peaks of the original machined taper surface can be best appreciated in the SEM image in figure 7. In order to study features deeper in the engagement area, we sectioned a female Articuleze head with moderate material loss of $1.50 \mathrm{~mm}_{3}$ which exhibited an obvious male taper imprint. The resulting images are shown in figures 8 and 9 .

\section{DISCUSSION}

The release of clinically significant amounts of metal debris from head neck taper junctions is neither limited to one manufacturer's products(19), nor large diameter MoM devices(6). It is imperative to develop a better understanding of taper failure in order to identify products currently implanted which may pose a risk to the patient, and also to inform the design and testing protocols of future products.

The results of this investigation indicate that the female taper surface finish appears to be an important variable in the release of metal debris from the taper junction. Tapers with surfaces composed of high isolated material peaks were associated with significantly greater material loss. This is perhaps unsurprising. High exposed surface asperities will lead to the generation of high localised contact stresses. The effect of this would be the release of particulate debris into the taper junction with the potential for third body wear. In keeping with our original hypothesis, images obtained from SEM and profilometry appeared to confirm the wearing away of the exposed peaks created via the machining process with associated abrasive wear. We accept that this is somewhat contrary to the classically accepted theory of mechanically assisted crevice corrosion.(20) However, we have previously described how Ti6Al4V, a material with a lower bulk hardness than the $\mathrm{CoCr}$ alloy used in Articuleze heads, could imprint its form on to CoCr via a corrosion assisted wear 
process.(9) We believe that this provides a sturdier explantation for the diffuse male taper imprint (figure 8 ) that was observed in over $50 \%$ of the retrieved specimens.

Of particular concern is the fact that the large diameter Articuleze head components examined in this study were not produced solely for use with MoM hips but also for use in conventional MoP devices. It is at present unclear whether the increasing number of reports of taper junction failure in current orthopaedic literature is secondary to the use of the MoM bearing surface itself or simply due to the fact that contemporary MoM devices exclusively employed large diameter components. But in the last decade there has been a global trend towards the use of larger head diameters irrespective of the type of bearing surface, be it MoP, MoM or ceramic combinations. The Pinnacle hip system remains one of the most widely used arthroplasty systems in the world in its MoP form.(21)

We were unable to examine the majority of the male stem tapers. Typically femoral stems, if well fixed, remain in situ as explantation may often mandate an extensive surgical procedure. However, the variation in taper angles and surface finish of the male tapers that we were able to analyse was small in comparison to the female tapers. Presumably because of the relative consistency in the manufacture of the male taper, the small regression analysis we conducted in this study showed no significant influence of the male taper morphology on the rate of taper wear.

Over $50 \%$ of variation in the taper wear rates were unaccounted for. It is likely that there are various patient factors (such as weight, activity, gait) as well as surgical factors (impaction force of head on to the stem(22) and contamination of the taper junction during surgery(23)) which play a role. Given the number of surgeons involved in procedures in the current paper, as well as increasing reports of taper failure worldwide(6), it appears that complications arising from the taper junction are however related to standard surgical practise.

In conclusion, the surface finish of the female taper surface appears to have an important effect on material loss at the taper interface. We recommend that this parameter be routinely assessed, reported and accounted for in simulator and retrieval studies.

\section{REFERENCES}

1. 12th Annual Report [Internet]. 2015.

2. Langton DJ, Jameson SS, Joyce TJ, Gandhi JN, Sidaginamale R, Mereddy P, et al. Accelerating failure rate of the ASR total hip replacement. J Bone Joint Surg Br. 2011;93(8):1011-6.

3. Jacobs JJ, Cooper HJ, Urban RM, Wixson RL, Della Valle CJ. What do we know about taper corrosion in total hip arthroplasty? J Arthroplasty. 2014;29(4):668-9.

4. Langton DJ, Jameson SS, Joyce TJ, Hallab NJ, Natu S, Nargol AV. Early failure of metal-on-metal bearings in hip resurfacing and large-diameter total hip replacement: A consequence of excess wear. J Bone Joint Surg Br. 2010;92(1):38-46.

5. Cooper HJ, Della Valle CJ, Berger RA, Tetreault M, Paprosky WG, Sporer SM. Corrosion at the head-neck taper as a cause for adverse local tissue reactions after total hip arthroplasty. The Journal of bone and joint surgery American volume. 2012;94.

6. Whitehouse MR, Endo M, Zachara S, Nielsen TO, Greidanus NV, Masri BA, et al. Adverse local tissue reactions in metal-on-polyethylene total hip arthroplasty due to trunnion corrosion: the risk of misdiagnosis. The bone \& joint journal. 2015;97-b(8):1024-30.

7. Marlowe DE, Parr JE, Mayor MB. Modularity of orthopedic implants: ASTM International; 1997.

8. Langton DJ, Sidaginamale R, Lord JK, Nargol AV, Joyce TJ. Taper junction failure in large diameter metal-on-metal bearings. Bone Joint Res. 2012;1(4):56-63.

9. Moharrami N, Langton DJ, Sayginer O, Bull SJ. Why does titanium alloy wear cobalt chrome alloy despite lower bulk hardness: A nanoindentation study? Thin Solid Films. 2013;549:79-86.

10. Brock TM, Sidaginamale R, Rushton S, Nargol AV, Bowsher JG, Savisaar C, et al. Shorter, rough trunnion surfaces are associated with higher taper wear rates than longer, smooth trunnion surfaces in a contemporary large head metal-on-metal total hip arthroplasty system. J Orthop Res.

2015;33(12):1868-74. 
11. Hothi HS, Whittaker RK, Meswania JM, Blunn GW, Skinner JA, Hart AJ. Influence of stem typeon material loss at the metal-on-metal pinnacle taper junction. Proc Inst Mech Eng $\mathrm{H}$.

2015;229(1):91-7.

12. 213 IT. Geometrical Product Specifications (GPS) - Surface texture: Profile method - Rules and procedures for the assessment of surface texture. 1996(2).

13. Langton DJ, Sidaginamale RP, Holland JP, Deehan D, Joyce TJ, Nargol AV, et al. Practical considerations for volumetric wear analysis of explanted hip arthroplasties. Bone Joint Res. 2014;3(3):60-8.

14. Matthies AK, Racasan R, Bills P, Blunt L, Cro S, Panagiotidou A. Material loss at the taper junction of retrieved large head metal-on-metal total hip replacements. J Orthop Res. 2013;31.

15. Zeng P, Rainforth WM, Cook RB. Characterisation of the oxide film on the taper interface from retrieved large diameter metal on polymer modular total hip replacements. Tribology International. 2015;89:86-96.

16. Panagiotidou A, Meswania J, Hua J, Muirhead-Allwood S, Hart A, Blunn G. Enhanced wear and corrosion in modular tapers in total hip replacement is associated with the contact area and surface topography. J Orthop Res. 2013;31(12):2032-9.

17. Bone MC, Sidaginamale RP, Lord JK, Scholes SC, Joyce TJ, Nargol AV, et al. Determining material loss from the femoral stem trunnion in hip arthroplasty using a coordinate measuring machine. Proc Inst Mech Eng H. 2015;229(1):69-76.

18. Schmidt AH, Loch DA, Bechtold JE, Kyle RF. Assessing Morse taper function: the relationship between impaction force, disassembly force, and design variables. Modularity of Orthopedic Implants. 1997;1301:114.

19. Matthies AK, Racasan R, Bills P, Blunt L, Cro S, Panagiotidou A, et al. Material loss at the taper junction of retrieved large head metal-on-metal total hip replacements. J Orthop Res. 2013;31(11):1677-85.

20. Jacobs JJ, Gilbert JL, Urban RM. Current Concepts Review-Corrosion of Metal Orthopaedic Implants*. The Journal of Bone \& Joint Surgery. 1998;80(2):268-82.

21. Wales NJRoEa. 12th Annual Report. 2015.

22. Rehmer A, Bishop NE, Morlock MM. Influence of assembly procedure and material combination on the strength of the taper connection at the head-neck junction of modular hip endoprostheses. Clinical biomechanics (Bristol, Avon). 2012;27(1):77-83.

23. Lavernia CJ, Baerga L, Barrack RL, Tozakoglou E, Cook SD, Lata L, et al. The effects of blood and fat on Morse taper disassembly forces. American journal of orthopedics (Belle Mead, NJ). 2009;38(4):187-90. 